\title{
EFFECTS OF LASER IRRADIATION ON NORMAL AND ANEMIC HUMAN BLOOD
}

\author{
Imad Al - Deen Hussein Ali Al - Saidi ${ }^{* 1} 凹$, Majdi Faisal Majeed ${ }^{2}$, Ikram Kamal Jasim \\ 3 \\ 1,3 Department of Physics, College of Education for Pure Sciences, University of Basrah, Basrah, \\ Iraq \\ 2 Department of Anatomy and Histology, College of Veterinary, Medicine, University of Basrah, \\ Basrah, Iraq
}

DOI: https://doi.org/10.29121/granthaalayah.v8.i8.2020.862

Article Type: Research Article

Article Citation: Imad Al - Deen Hussein Ali Al - Saidi, Majdi Faisal Majeed, and Ikram Kamal Jasim. (2020). EFFECTS OF LASER IRRADIATION ON NORMAL AND ANEMIC HUMAN BLOOD. International Journal of Research GRANTHAALAYAH, 8(8), 256-261. https://doi.org/10.29121/granthaa layah.v8.i8.2020.862

Received Date: 25 July 2020

Accepted Date: 31 August 2020

Keywords:

Laser Irradiation

Normal and Anemic Human Blood Optical Properties of Human Blood

\begin{abstract}
The effects of laser irradiation on the whole human blood were studied. The blood samples were taken from healthy donors with normal blood and donors with anemic blood. The blood samples were exposed to laser radiation. Two lasers of the same types, continuous wave (CW) diode pumped solid-state lasers (DPSSL' s) were used to irradiate the blood samples. One of these laser has a wavelength $532 \mathrm{~nm}$ (green laser beam), while the other laser has a wavelength $671 \mathrm{~nm}$ (red laser beam). The output power of the two lasers can be varied over the range $0-100 \mathrm{~mW}$. In the present study, the output power was fixed at $20 \mathrm{~mW}$ for both lasers. The blood samples were exposed to different irradiation times, 5, 15, and 30 min. Significant changes in the optical parameters of the irradiated blood samples were observed in comparison with that of the un-irradiated blood samples (the control samples). These optical parameters were determined from the measured absorbance spectra of the un-irradiated and irradiated samples. The absorbance spectra were measured using a UV-Visible double-beam spectrophotometer operating over the wavelength range $190-1100 \mathrm{~nm}$.

The results of the present study revealed that the laser irradiation can produce considerable effects on the human blood samples, suggesting the suitability of the laser beam irradiation for the biological and medical applications.
\end{abstract}

\section{INTRODUCTION}

Laser beam radiation has been widely used in a variety of applications, such as, physical, chemical, biological, and medical fields [1], [2], [3], [4], [5], [6], [7]. The advantage of using the laser beam in these fields is due to its distinctive characteristics. The laser emits intense, monochromatic, and coherent beam. Furthermore, the laser beam can be easily controlled and its highly collimated nature enables it to be focused into a small area to provide high incident intensity [8].

Investigation of the effects of interaction of laser radiation with biological tissues and blood is of great interest and has received considerable attention [4], [5], [9], [10], [11], [12], [13], [14].

(C) 2020 The Author(s). This is an open access article distributed under the terms of the Creative Commons Attribution License, which permits unrestricted use, distribution, and reproduction in any medium, provided the original author and source are credited. 
It is shown that the laser beam irradiation is most useful in the biomedical applications and can be effectively used for the biological and medical treatments [1], [6], [7], [9], [10], [11], [12], [13], [14], [15], [16]. It has been found that the laser beam can produce some optical and chemical effects when it interacts with the biological tissues and the human blood. These effects, in turn, will cause significant changes in the optical parameters of these biological tissues and human blood, such as, absorbance, transmittance, reflectance, absorption coefficient ( $\alpha$ ), and refractive index (n) [4], [9], [10], [11], [15], [17], [18]. It is found that these changes depend on the structure of the human body tissues, as well as the wavelength and the flounce (the dose) of the applied laser beam.

There are several techniques can be used to examine the changes in the optical properties of the biological tissues and human blood and also to measure their parameters [18], [22], [23], [24]. Among these techniques, is the UV-Visible absorption spectroscopy, which is a simple, quick, non-destructive, and relatively accurate technique of analyzing biological materials [12], [23], [25]. With this technique, the absorption spectra of the biological tissue or the human blood samples are analyzed and recorded, before and after exposing to the laser beam, using a spectrophotometer.

Although there are some of studies have been performed, using different techniques, to examine the changes in the biological parameters due to the interaction processes inside the biological tissues, but still more studies are needed to extend our knowledge and understanding about the responses of the biological tissues and blood to the laser radiation. Such studies are essential to get further information regarding the chemical and physical properties of the biological tissues and human blood.

The aim of the present study is to evaluate the effect of the laser beam irradiation on the biological parameters of the normal and anemic human blood samples. The absorbance spectra of these samples were measured for two different wavelengths and different irradiation (exposure) times.

\section{SAMPLES PREPARATION}

Human blood samples were collected from 10 healthy donors and 10 donors with anemia disease. $3 \mathrm{ml}$ of blood were taken from each donor. These blood samples were collected in glass tubes containing Ethylene Diamine Tetraacetic Acid (EDTA) as an anticoagulant. Each sample of the normal blood and anemic blood was divided into three samples of equal volumes, one of these samples was used as a control sample (un-irradiated sample), while the other two samples were used as irradiated samples. The blood was diluted with $\mathrm{NaCl}$ solution (normal saline solution), $1 \mathrm{ml}$ of $\mathrm{NaCl}$ solution for each $20 \mu \mathrm{l}$ of blood the blood of each sample was gently shaken before irradiation to obtain a homogeneous fluid.

\section{LASER IRRADIATION AND MEASUREMENTS}

Two continuous wave (CW) lasers of the same type, diode pumped solid-state lasers (DPSSL's), but with different wavelengths, $532 \mathrm{~nm}$ (green laser beam) and $671 \mathrm{~nm}$ (red laser beam), were used in the present study. The output power of each laser can be varied over the range $0-100 \mathrm{~mW}$. In the present study, the output power was fixed at 20 $\mathrm{mW}$ for both two lasers. Each laser was placed vertically at a distance $6 \mathrm{~cm}$ from the blood surface, and the laser beam was incident normally, from up to down, toward the blood sample. The output power of the laser was measured by using a photo-detector connected to digital power meter.

The laser beam is a Gaussian single transverse mode $\left(\mathrm{TEM}_{00}\right)$ and has a diameter of $4 \mathrm{~mm}$. Before sample irradiation, the blood was decanted into $1 \mathrm{~cm}$ cuvette. The blood samples were irradiated with the laser beam at different irradiation times, 5, 15, and $30 \mathrm{~min}$, for each wavelength, separately. The delivered flounces (the exposure doses) corresponding to the irradiation times are, 47.77, 143.32 , and $286.63 \mathrm{~J} / \mathrm{cm}^{2}$, respectively.

The absorption spectra of the un-irradiated and the irradiated blood samples, for the normal blood and anemic blood, were measured and analyzed before and after irradiation by using double - beam spectrophotometer (Cecil Model CE - 7500) of the wavelength range 190 - $1100 \mathrm{~nm}$.

\section{RESULTS AND DISCUSSION}

Two groups of both the normal blood and anaemic blood were irradiated with laser beam of the wavelength $532 \mathrm{~nm}$ (green laser beam) and with laser beam of the wavelength $671 \mathrm{~nm}$ (red laser beam), (not the same samples), 
for different irradiation (exposure) times, 5, 15, and $30 \mathrm{~min}$. Two blood samples were left without irradiation, one for the normal blood and the other for the anaemic blood, were used as control samples. The absorption spectra of the control (un-irradiated) samples and the irradiated samples of the normal blood and the anemic blood were measured and analyzed using the double - beam spectrophotometer over the wavelength range $300-900 \mathrm{~nm}$ in the ultraviolet and the visible ((UV - Visible) regions. Figs. (1) - (4) show the representative examples of the measured absorption spectra of the control blood samples and the irradiated samples of the normal blood and anemic blood irradiated with laser beam at the wavelength $532 \mathrm{~nm}$ and $671 \mathrm{~nm}$ for different irradiation times. It is clearly seen in these figures that the absorbance of the blood samples are significantly affected by the presence of the laser irradiation and their absorbance increased as the irradiation time increased. Four bands with peaks of different absorbance values are observed in these absorption spectra.

In Fig. 1, the most intense (the maximum height) peaks are observed at the wavelength $\lambda_{\max }=415 \mathrm{~nm}$, while the other peaks with less absorbance values are located at the wavelengths, 346, 546, and $577 \mathrm{~nm}$. The values of the absorbance at the wavelength $415 \mathrm{~nm}$ are, 1.387, 1.993, and 2.324 (Arb. Units) for the irradiation times, 5, 15, and 30 min, respectively.

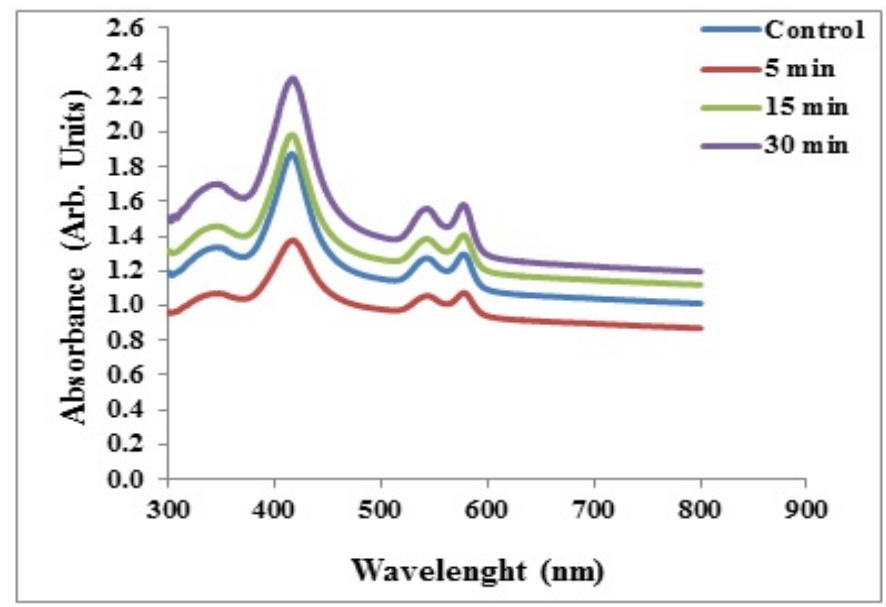

Figure 1: Absorbance spectra of the control normal blood sample and the irradiated normal blood samples with laser radiation at the wavelength $532 \mathrm{~nm}$, for different irradiation times.

Fig. (2), shows the absorption spectra of the control blood samples and the anemic blood samples irradiated with the laser beam of the wavelength $532 \mathrm{~nm}$, for the irradiation times, 5, 15, and $30 \mathrm{~min}$. The values of absorbance of the control blood samples and the irradiated samples of the anaemic blood at the wavelength $415 \mathrm{~nm}$ are, 0.848 , $1.429,1.250$, and 2.010 (Arb. Units). It is clearly seen that the values of the absorbance of the anemic blood samples are smaller than those obtained from the normal blood samples.

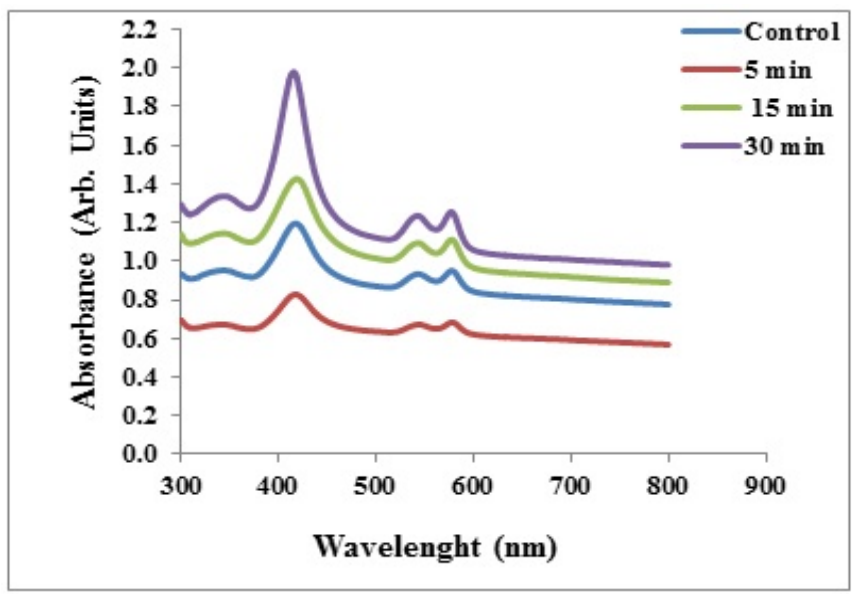

Figure 2: Absorbance spectra of the control anemic blood sample and the irradiated anemic blood samples with laser radiation at the wavelength $532 \mathrm{~nm}$, for different irradiation times. 
The absorption spectra of the control blood sample and the normal blood samples irradiated with the laser beam of the wavelength $671 \mathrm{~nm}$ for different irradiation times is shown in Fig. 3. It is noticed that the spectral peaks of the absorbance are dropped down compared to those of the normal blood samples irradiated with the laser beam of the wavelength $532 \mathrm{~nm}$. The absorbance values at the most intense peak at the wavelength $415 \mathrm{~nm}$ are, 1.129 , $1.355,1.548$, and 1.903 (Arb. Units), which are smaller than the absorbance values of the normal blood samples irradiated with the laser beam at the wavelength $532 \mathrm{~nm}$.

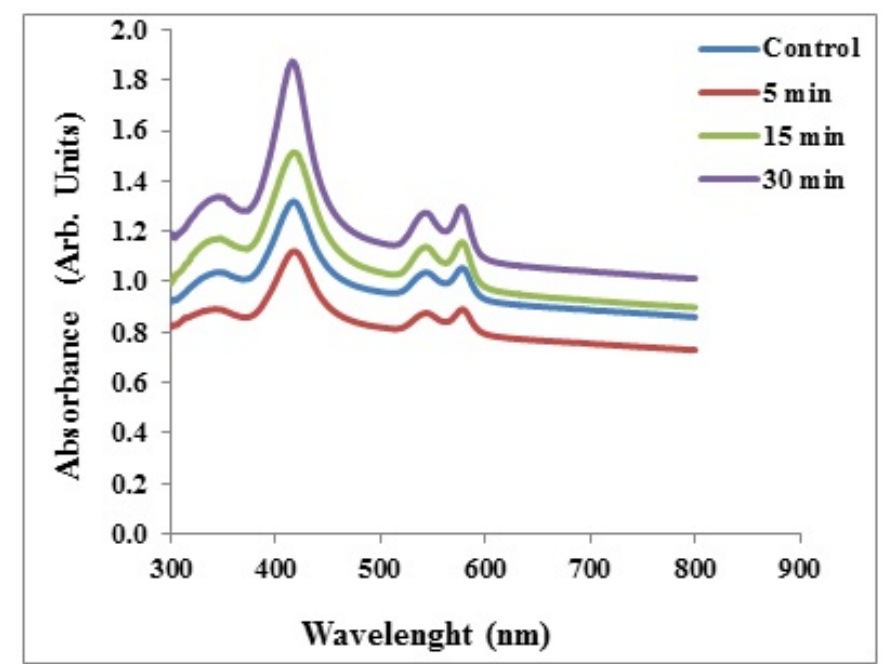

Figure 3: Absorbance spectra of the control normal blood sample and the irradiated normal blood samples with laser radiation at the wavelength $671 \mathrm{~nm}$, for different irradiation times.

Fig. 4 illustrates the absorption spectra of the of the control blood sample and anemic blood samples irradiated with the laser beam of the wavelength $671 \mathrm{~nm}$, for different irradiation times, 5, 15, 30 min. The absorbance values of the blood samples at the most intense peak at the wavelength $415 \mathrm{~nm}$ are, $0.900,1.29,1.171$, and 1.430 (Arb. Units). Comparison between these absorbance values and those of the normal blood samples irradiated with the laser beam at the same wavelength $671 \mathrm{~nm}$ (Fig. (3)), show again that these values are smaller than the absorbance values of the normal blood samples. Thus, it can be concluded that the anemic blood is less affected by changing the wavelength of the irradiated laser beam. As for the normal blood samples, the reduction of the absorbance values of the anemic blood samples is observed when the samples are irradiated with the laser beam of the wavelength $671 \mathrm{~nm}$.

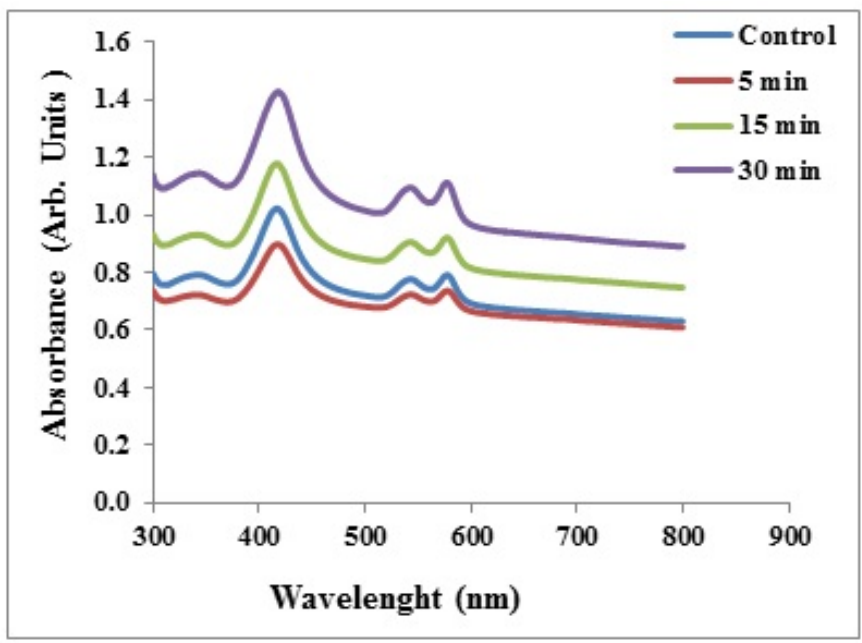

Figure 4: Absorbance spectra of the control anemic blood sample and the irradiated anemic blood samples with laser radiation at the wavelength $671 \mathrm{~nm}$, for different irradiation times. 
The absorbance values of the normal blood samples and the anemic blood samples before and after irradiation with laser beam of the wavelengths $532 \mathrm{~nm}$ and $671 \mathrm{~nm}$, for different irradiation times are summarized in Tables (1) and (2), respectively.

Table 1: The calculated absorbance values of the normal blood samples and the anemic blood samples before and after irradiation with a laser radiation beam of the wavelength $532 \mathrm{~nm}$, for different irradiation times.

\begin{tabular}{|c|c|c|c|c|c|c|c|c|}
\hline \multirow{2}{*}{$\begin{array}{c}\text { wave length }(\lambda) \\
\text { nm }\end{array}$} & \multicolumn{4}{|c|}{ Normal blood sample } & \multicolumn{4}{c|}{ Anemic blood sample } \\
\cline { 2 - 9 } & \multicolumn{3}{|c|}{ Absorbance (Arb. Units) } & \multicolumn{3}{c|}{ Absorbance (Arb. Units) } \\
\cline { 2 - 9 } & Control & 5 min & 15 min & 30 min & Control & 5 min & 15 min & 30 min \\
\hline 346 & 1.335769 & 1.070421 & 1.458092 & 1.701011 & 0.951752 & 0.671302 & 1.142668 & 1.335871 \\
\hline 415 & 1.870673 & 1.372570 & 1.981901 & 2.292962 & 1.190861 & 0.825268 & 1.417014 & 1.977784 \\
\hline 546 & 1.269117 & 1.053517 & 1.378035 & 1.549943 & 0.950056 & 0.682982 & 1.110698 & 1.254708 \\
\hline 577 & 1.296977 & 1.073465 & 1.406218 & 1.581906 & 0.982315 & 0.699989 & 1.168890 & 1.329378 \\
\hline
\end{tabular}

Table 2: The calculated absorbance values of the normal blood samples and the anemic blood samples before and after irradiation with a laser radiation beam of the wavelength $671 \mathrm{~nm}$, for different irradiation times.

\begin{tabular}{|c|c|c|c|c|c|c|c|c|}
\hline \multirow{2}{*}{$\begin{array}{c}\text { wave length }(\lambda) \\
\text { nm }\end{array}$} & \multicolumn{4}{|c|}{ Normal blood sample } & \multicolumn{4}{c|}{ Anemic blood sample } \\
\cline { 2 - 9 } & \multicolumn{3}{|c|}{ Absorbance (Arb. Units) } & \multicolumn{3}{c|}{ Absorbance (Arb. Units) } \\
\cline { 2 - 9 } & Control & $5 \mathrm{~min}$ & $15 \mathrm{~min}$ & $30 \mathrm{~min}$ & Control & $5 \mathrm{~min}$ & $15 \mathrm{~min}$ & $30 \mathrm{~min}$ \\
\hline 346 & 1.038876 & 0.890357 & 1.171367 & 1.336358 & 0.790886 & 0.721246 & 0.929500 & 1.142668 \\
\hline 415 & 1.317066 & 1.118843 & 1.511248 & 1.874721 & 1.017404 & 0.893002 & 1.172712 & 1.417014 \\
\hline 546 & 1.054593 & 0.890569 & 1.157263 & 1.297246 & 0.774112 & 0.722033 & 0.902981 & 1.091515 \\
\hline 577 & 1.074430 & 0.919262 & 1.206173 & 1.346185 & 0.790042 & 0.735035 & 0.919351 & 1.110698 \\
\hline
\end{tabular}

\section{CONCLUSIONS}

In the present study, the effect of laser radiation on the properties of the healthy (normal) and anemic human blood samples was investigated. Two continuous wave (CW) diode pumped solid - state lasers (DPSSL's) with different wavelengths, $532 \mathrm{~nm}$ and $671 \mathrm{~nm}$ were used for this study. The absorption spectra of the samples were analyzed by using the UV - Visible range absorption spectroscopy. This is an important technique can be used for measuring the properties of the biological materials such as, tissues and blood component. It is a simple, quick, and nondestructive method after analyzing and medical treatment of the biological materials. Results can be provided useful information about the change in the biological parameters due to the effect of the laser radiation.

It is observed there is a clear difference between the absorbance spectra of the healthy blood and anemic blood samples for both the wavelengths used, $532 \mathrm{~nm}$ and $671 \mathrm{~nm}$. The technique that used in the present study can be considered as a suitable technique to distinguish between the healthy (normal) blood and anemic blood.

\section{SOURCES OF FUNDING}

This research received no specific grant from any funding agency in the public, commercial, or not-for-profit sectors.

\section{CONFLICT OF INTEREST}

The author have declared that no competing interests exist.

\section{ACKNOWLEDGMENT}

None. 


\section{REFERENCES}

[1] A. N. Rubinov,"Physical Grounds for Biological Effect of Laser Radiation", J. Phys. D: Appl. Phys., 36.19 (2003) 2317-2330.

[2] S. Restegar, B. Kim and L. Jacques, "Role of Temperature Dependence of Optical Properties in Laser Irradiation of Biological Tissue", Proc. SPIE, Vol. 1646, (1992) 228-231.

[3] M. S. Strikman, K. Spartalia, and M.W. Cole, Applications of Modern Physics in Medicine, (Princeton University Press, 2014).

[4] M. H. Niemz, Laser - Tissue Interaction: Fundamentals and Applications (Biological, Medical, Physics, and Biomedical Engineering), 4th Edition (Springer, New York, USA, 2019).

[5] G. R. Kulkarni, " Laser Tissue Interaction Studies for Medicine ", Bull. Mater. Sci., 11 (1988) 239-244.

[6] E. Mester, A. F. Mester and A. Mester, The Biomedical Effects of Laser Application, Laser Surg. Med., 5 (1988) 31-39.

[7] B. Azadgoli and R. V. Baker, "Laser Applications in Surgery" (Review Article on Innovations Technology in Surgery) Ann. Transl. Med., 4 (2016) 452-458.

[8] O. Svelto, Principles of Laser, 5th Edition, (Springer Science + Business Media LLC, New York, USA, 2010).

[9] P. Di Giacomo, S. Oriando, M. Dell Ariccia, and B. Brandimare, " Low Level Laser Therapy: Laser Radiation Absorption in Biological Tissues ", Appl. Phys., 112 (2013) 71-75.

[10] S. L. Jacques, " Optical Properties of Biological Tissues: A Review", Phys. Med. Bilog., 58 (2013) 37- 61.

[11] J. Zdrojkowski and N. Pisharoty, " Optical Transmission and Reflection by Blood ", IEEE Transactions on Biomedical Engineering, 17 (1970) 122-128.

[12] V. H. Ghadage and B. N. Zaware, " Study the Effect of He - Ne (He-Ne) Laser Irradiation on Normal Human Blood In vitro Using FTIR Technique", IOSR, J. Pharmacy and Biological Sciences, 13 (2008)1-5.

[13] H. Ma, Y. Yang, and S. Cherng, " Interaction of Excimer Laser with Blood Components and Thrombosis ", Life Science (2008) 19-26.

[14] G. A. Zaiesskaya, E. G. Sambor, "Interaction of Low - intensity Laser Radiation with Blood and Components ", J. APPI - Sepectrosc., 72 (2005), 242-248.

[15] W. F. Cheong, S. A. Prahl, and A. J. Welch, "A Review of the Optical Properties of Biological Tissues", IEEE Quant. Electron., 26.12 (1990): 2166-2185.

[16] J. D. Bronzino, and D. R. Peterson, (Ed.), (The Biomedical Engineering Handbook), 4th Edition (CRC Press, Florida, USA, 2015).

[17] T. Halldorsson," Alteration of Optical Properties of Blood by Nd: YAG Laser Irradiation ", In Proc. 4th Cong. Int. Soc. Laser Surgery, Tokyo, Japan, Nov. (1981) 1-8.

[18] J. K. Barton, D. P. Popok, and J.F. Black, "Thermal Analysis of Blood Undergoing Laser Photocoagulation ", IEEE J. Quant. Electron., 7 (2001) 936- 943.

[19] J. Cai (Ed.), Atomic Force Microscopy in Molecular and Cell Biology, (Springer, New York, USA, 2018).

[20] W. A. Hendrickso, "X -Rays in Molecular Biophysics", Physics Today, 48 (1995) 42-50.

[21] K. Wilson, and J. Wlaker (Eds.), Principles and Techniques of Biochemistry and Molecular Biology, 8th Edition, (Cambridge University Press, Cambridge, UK, 2018).

[22] Y. Cui, Z. Guo, Y. Zhao, Y. Zheng, Y. Qiao, J. Gai,and S. Liu, " Reactive Effect of Low Intensity He-Ne Laser Upon Damaged Ultra Structure of Human Erythrocyte Membrane in Fenton System by Atomic Force Microscope " Acta Biochemica et Biophysica Sinica , 39 (2007) 484-489.

[23] T. Chelidze, " Dielectric Spectroscopy of Blood ", J. Non - Crystalline Solids, 305 (2002) 285-294.

[24] M. Qiany, J. Chen, Z. Junliang and L. Welzhou, "In Vitro Effects of He-Ne Laser Irradiation on Human Blood: Blood Viscosity and Deformability of Erythrocytes ", Photo Medicine and Laser Surgery, 22 (2004) 477- 482.

[25] R. Lubart, Y. Wollman, H. Friedmann, S. Rochkind, and I. Laulicht, " Effects of Visible and Infrared Laser on Cell Culture," J. Photochem., Photobiolog., B, 12 (1992) 305- 310. 